\title{
Reversible photocontrol of oxidase activity by inserting a photosensitive domain into the oxidase
}

\author{
Tongjing Sun, Baoqi Zhang, Jinping Lin and Yuhong Ren ${ }^{*}$
}

\begin{abstract}
Background: Photocontrol of protein activity has become a helpful strategy for regulating biological pathways. Herein, a method for the precise and reversible photocontrol of oxidase activity was developed by using the conformational change of the AsLOV2 domain.

Results: The AsLOV2 domain was inserted into the nonconserved sites exposed on the surface of the AdhP protein, and the alov9 fusion was successfully screened for subsequent optical experiments under the assumption that neither of these actions affected the original activity of AdhP protein. The activity of alov9 was noticeably inhibited when the fusion was exposed to $470 \mathrm{~nm}$ blue light and recovered within $30 \mathrm{~min}$. As a result, we could precisely and reversibly photocontrol alov9 activity through the optimization of several parameters, including cofactor concentration, light intensity, and illumination time.

Conclusions: An efficient method was developed for the photoinhibition of enzymatic activity based on the insertion of the light-sensitive AsLOV2 domain, providing new ideas for photocontrolling metabolic pathways without carriers in the future.
\end{abstract}

Keywords: AsLOV2, Enzyme activity, Insertion, Oxidase, Photocontrol

\section{Background}

Photocontrol of protein dynamics is a powerful tool for the precise spatial and temporal control of signal transduction (Pathak et al. 2014; Zhang and Cui 2015). The light-sensitive LOV2 domain of Avena sativa phototropin 1 (AsLOV2) is part of the PAS superfamily of domains (Crosson and Moffat 2001), each of which consists of a flavin nucleotide and a C-terminal J $\alpha$ helix (Harper et al. 2003; Halavaty and Moffat 2007). During the conformational change of the AsLOV2 domain, the J $\alpha$ helix will unfold under illumination (Harper et al. 2004; Swartz et al. 2002), and thus it has been utilized to construct engineered optical switches. As a photosensitive element, the AsLOV2 domain has many advantages, including high spatial and temporal resolution, fast response to

\footnotetext{
*Correspondence: yhren@ecust.edu.cn

State Key Laboratory of Bioreactor Engineering, New World Institute of Biotechnology, East China University of Science and Technology,
} Shanghai, China blue light, and good reversibility (Lee et al. 2014). Therefore, the AsLOV2 domain has been widely used as an engineered light switch in recent years.

There are two general approaches to achieve the photocontrol of proteins based on the AsLOV2 domain. One is based on the peptide-tagged LOV2 domain (Kawano et al. 2015). Devin et al. developed tunable light-inducible dimerization tags (TULIPs) to control protein localization (Strickland et al. 2012). The other approach is based on peptide-binding (Lungu et al. 2012). Hui et al. constructed the LOVTRAP system for reversible lightinduced protein dissociation (Wang et al. 2016). Most studies have focused on interfering protein-protein interactions (PPIs) using the photosensitive domain, but studies have only rarely concentrated on the kinetics of individual proteins. Here, a method was introduced for achieving reversible photocontrol of oxidase AdhP in time and space based on insertion of the AsLOV2 domain. 
In our work, the LOV2 domain was inserted into surface-exposed and evolutionarily nonconserved sites of the AdhP protein to prevent possible structural perturbations. The AdhP was cloned from E. coli MG1655 and catalyzes the oxidation-reduction reactions of shortchain alcohols and aldehydes (Thomas et al. 2013). The $10 \AA$ spacing between its $\mathrm{N}$ and $\mathrm{C}$ termini prevented structural interference of the original protein (Dagliyan et al. 2016). Therefore, we assumed that when the LOV2 domain underwent a conformational change upon illumination, its disorder can be efficiently transmitted to the active center of the AdhP protein to produce a structural disturbance, which would inhibit the activity of the AdhP protein.

\section{Materials and methods}

\section{Cloning, expression, and purification of enzymes}

The gene for AdhP was subcloned into pET-28a $(+)$ via BamHI/XhoI (Thermo Fisher Scientific, Rockford, IL, USA) restriction sites to create an in-frame $\mathrm{N}$-terminal 6*histidine tag. The LOV2 and adhP genes were spliced together using the splicing by overlap extension polymerase chain reaction method (SOE-PCR) (the primer information is listed in Additional file 1: Table S1) (Chen et al. 2016). The plasmids were then transformed into Escherichia coli BL21 (DE3)-competent cells.

The recombinant $E$. coli BL21 (DE3) was incubated in lysogeny broth (LB) containing $50 \mathrm{mg} / \mathrm{L}$ kanamycin at $37{ }^{\circ} \mathrm{C}$. When the $\mathrm{OD}_{600}$ reached approximately 0.6 , enzyme expression was induced by the addition of $0.1 \mathrm{mM}$ IPTG (final concentration). The culture was incubated at $18{ }^{\circ} \mathrm{C}$ for an additional $12 \mathrm{~h}$ at $200 \mathrm{rpm}$. After centrifugation $\left(6000 \times g, 10 \mathrm{~min}, 4{ }^{\circ} \mathrm{C}\right)$ and washing with $0.9 \% \mathrm{NaCl}$, the cells were resuspended in $20 \mathrm{mM}$ sodium phosphate buffer $(\mathrm{pH} 8.5)$ and disrupted by ultrasonication. After centrifugation $(12,000 \times g, 30 \mathrm{~min}$, $4{ }^{\circ} \mathrm{C}$ ), the crude extract was used for protein purification using a 5-mL HisTrap FF crude column (GE Healthcare, Waukesha, WI, USA). The protein was eluted with an increasing gradient from 20 to $500 \mathrm{mM}$ of imidazole in sodium phosphate buffer. Proteins were evaluated using SDS-PAGE, and the concentration was conducted using a Bradford assay kit (Beyotime, Shanghai, China). The purified enzyme was concentrated and stored at $-20{ }^{\circ} \mathrm{C}$ for further use.

\section{Enzyme assay}

Enzyme activity was determined by measuring the rate of $\mathrm{NAD}^{+}$reduction at $340 \mathrm{~nm}$ on an ultraviolet (UV)/visible spectrophotometer (BioTek Instruments, Winooski, VT, US); a molar extinction coefficient of $6.22 \mathrm{mM}^{-1} \mathrm{~cm}^{-1}$ for NADH was used for the calculation (Zhang et al. 2002). Standard reactions were performed in $200 \mu \mathrm{L}$ of sodium phosphate buffer $(100 \mathrm{mM}, \mathrm{pH} 8.5)$ at $30{ }^{\circ} \mathrm{C}$ containing $0.2 \mathrm{mM} \mathrm{NAD}^{+}, 5 \mathrm{mM}$ substrate (in $5 \% \mathrm{v} / \mathrm{v}$ DMSO), and an appropriate amount of purified enzyme. One unit of enzyme activity was defined as the reduction of $1 \mu \mathrm{mol}$ geraniol per minute. The light group activity was measured immediately after irradiation for a precise period. Specific wavelength $470 \mathrm{~nm}$ LED light sources was used for blue light illumination. All of the measurements were carried out over $2 \mathrm{~min}$ and performed at least three times.

\section{Structure analysis and homology modeling}

The structural model of alov9 was built using the modeler 9.20 program (Schwede et al. 2003). The crystal structure of AdhP (PDB ID: 4kgv) and AsLOV2 domain (PDB ID: $5 \mathrm{hzj}$ ) were used as templates. Model evaluation was performed using the Ramachandran plot Web server (Betteridge et al. 2003). Ramachandran plot analysis results showed that $95.4 \%$ of the total number of residues was in the favored and allowed region for alov9. The model could be considered reliable only if the percentage of residues in the favored and allowed region was greater than $90 \%$. Thus, the evaluation results indicated that our model of alov9 was reliable. Structural analysis was performed using the PyMOL 1.8.0 program.

\section{Results and discussion}

\section{Strategies to inhibit AdhP activity}

As described above, we hypothesized insertion of a light-sensitive domain at the active sites around catalytic center could lead to optogenetic control of AdhP. Our experiment is organized as follows: First, insertion sites were selected on the surface-exposed loops of AdhP by analyzing the crystal structure to avoid possible structural interference (Fig. 1a). Eighteen allosteric sites were selected in this round. Then non-conservative active sites were selected from those exposed sites by sequence alignment (Fig. 1b). Ten sites were finally identified as insertion sites. Finally, sensory domain was inserted into those insertion sites to form fusion Lov2-AdhP, here called alov1-10 (Additional file 1: Figure S1). All of the fusions can achieve soluble expression (Additional file 1: Figure S2).

To establish whether fusion enzyme activity remains stable after insertion into the sensitive domain, activity assays were performed in a catalytic system using a microplate reader. The results showed that the activity of these 10 fusions had varying degrees of reduction except the insertion of ninth point (Thr215) (Fig. 1c), which might be caused by the insertion of AsLOV2 at the ninth site on the surface of the AdhP protein and prevents influencing the correct folding of the AdhP protein. The results confirmed that insertion of LOV2 domain causes 

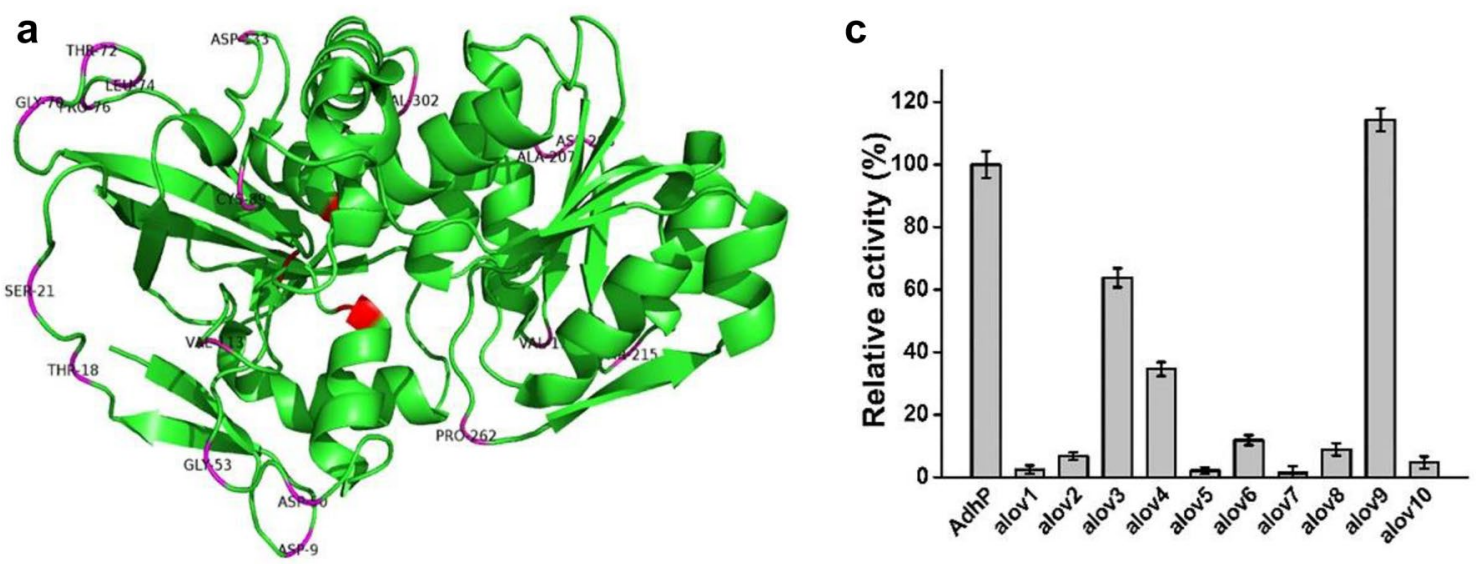

b adhP adhP
1 LLU
$1 \mathrm{RJW}$
$3 \mathrm{MEQ}$
$3 \mathrm{SII}$
$4 \mathrm{EEZ}$
$4 \mathrm{Z} 6 \mathrm{~K}$ $\alpha 5$

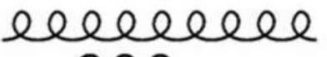
200

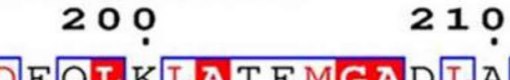

$\beta 11$ 210 $\alpha 6$

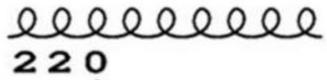
220

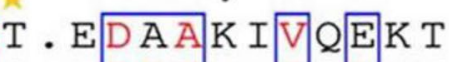

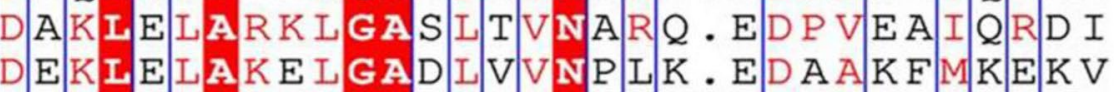

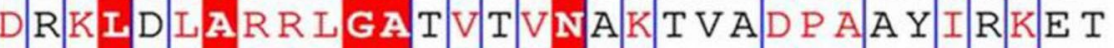
$D A K I N L A R R I$ G A EV AVNARD . TD P A A W L Q K E I QDKINIAKK I G A D V T I N S GD . V N P V|D E I K K I T

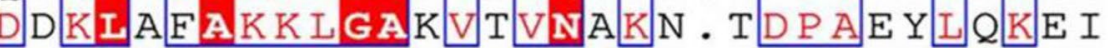

Fig. 1 Designing alovX (X present different insertion sites) photoswitches. a Crystal structure analysis of wild-type AdhP protein to select surface-exposed loop (red represents active center of AdhP. Magenta represents exposed sits in surface loop). $\mathbf{b}$ Screening unconservative sites from surface-exposed loops by sequence alignment (yellow star represents the selected site. The information of ten sites at Additional file 1: Figure S3). c Comparing catalytic activity between WT AdhP and alov1-10 fusions in the dark state. Error bars show SEM $(n=3)$

different structural interferences to the AdhP protein. From the perspective of maintaining stable protein activity, alov9 fusion was selected for a subsequent study.

\section{Optical inhibition enzyme activity}

To evaluate the inhibitory activity of the alov9 in response to specific wavelength $(470 \mathrm{~nm})$ of illumination, the activity of AdhP and alov9 was measured under dark and light conditions, respectively. In vitro activity assays revealed that the alov9 fusion was indeed strongly inhibited upon exposure to blue light (Fig. 2a), whereas the control group AdhP, in both the presence and absence of irradiation, displayed similar activities (Fig. 2a). These data indicated that the J $\alpha$ helix unfolding of the AsLOV2 protein upon illumination caused a structural disturbance in the AdhP protein, which caused a change in the substrate channel and a decrease in enzyme activity at last. The conformational change of enzyme influenced by illumination can be further confirmed by an experiment based on the Circular Dichroism date. As shown in Additional file 1: Figure S4, the alov9 without illumination showed an abundant $\alpha$-helix at $208 \mathrm{~nm}$ and $222 \mathrm{~nm}$ negative peak and $\beta$-sheet at the 195-198 nm positive peak. After illumination, the circular dichroism value of $\alpha$-helix and $\beta$-sheet of alov9 increased significantly. This indicated that the alov9 undergoes a conformational change upon illumination, which led to a decrease in oxidase activity. All of the results confirmed that LOV2 insertion could markedly inhibit the activity of AdhP under illumination.

The FMN cofactor is necessary for the unfolding of the AsLOV2 protein in the blue state (Christie et al. 1998). It has been confirmed that the incorporation of cofactor FMN is required for the light sensitivity of alov9 (Yu et al. 2016). As expected, the catalytic activity of alov9 in the absence of cofactor FMN did not decrease under irradiation (Fig. 2b). The data indicated that the participation of cofactor FMN is required in the next optical experiment.

\section{Exploration of factors affecting optical suppression}

To precisely photocontrol alov9 in time and space, several parameters were optimized that affect optical 

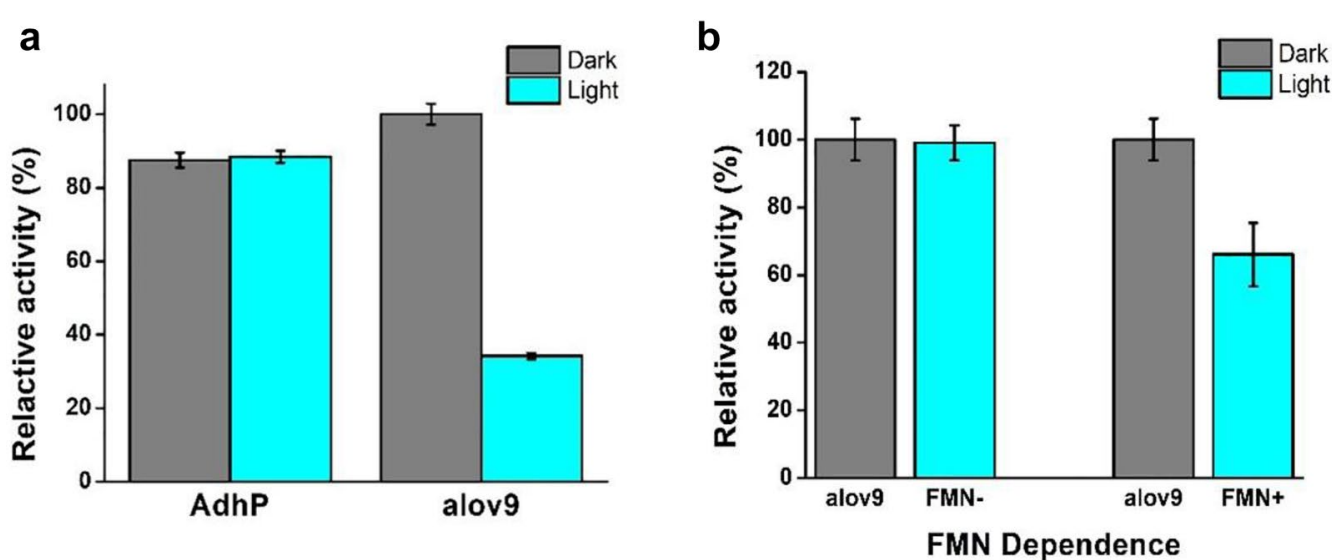

Fig. 2 Optical suppression of alov9 protein. a Enzyme activity assay shows that alov9's catalytic activity is inhibited upon irradiation. b Dependence of alov9 protein on cofactor FMN. Under the experimental conditions, the relative activity was expressed as a percentage of the maximum activity $(100 \%$ activity $=7.19 \mathrm{U} / \mathrm{mg})$. All error bars show SEM $(n=3)$
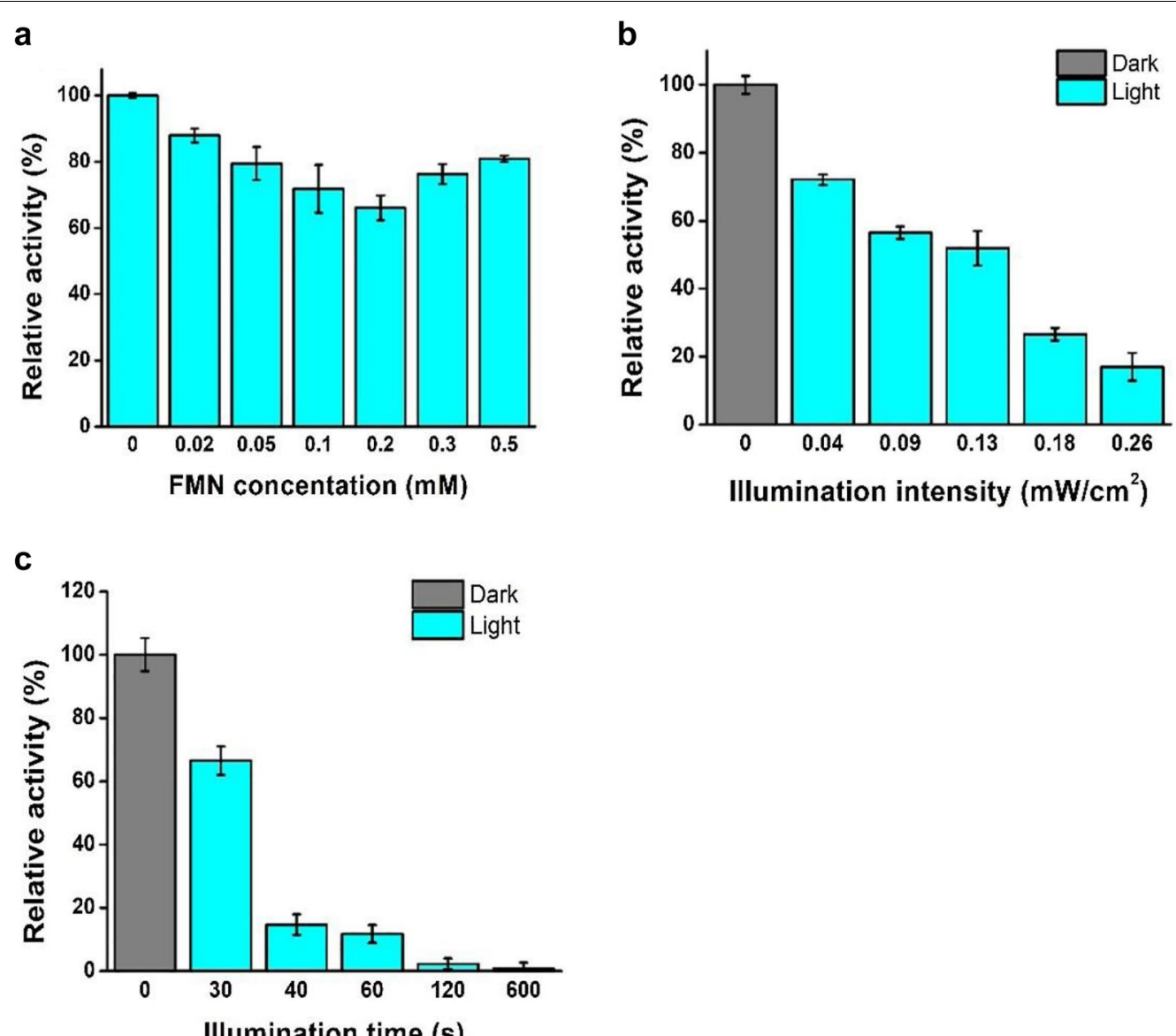

Fig. 3 Optical suppression factors. a Relationship between FMN concentration and the enzyme inhibition under irradiation at $470 \mathrm{~nm}$ for the same time. b Power dependency of alovg's inhibition under illumination at $470 \mathrm{~nm}$ for the same time. $\mathbf{c}$ Relationship between illumination time and alov9's inhibition under irradiation at $470 \mathrm{~nm}$. All error bars show SEM $(n=3)$ 
a

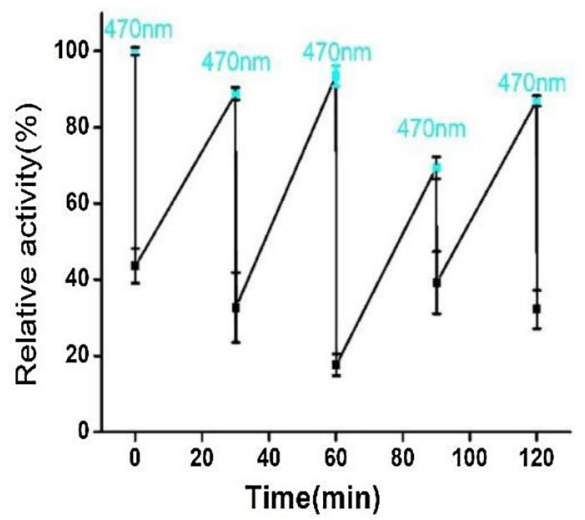

b

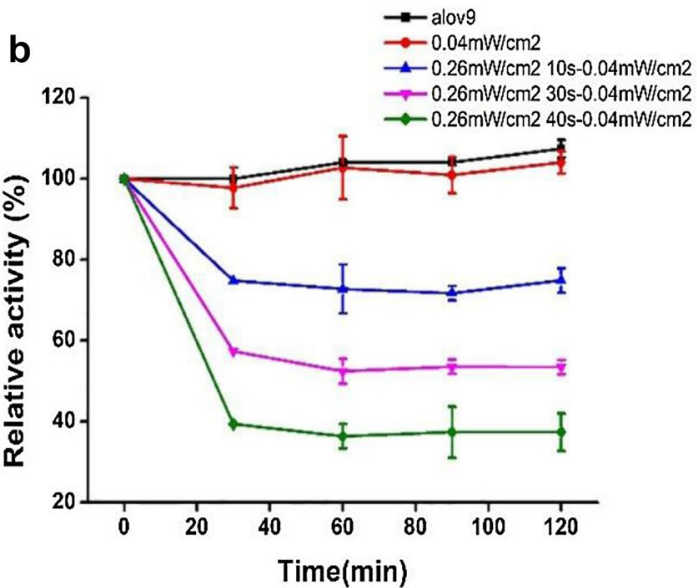

Fig. 4 Reversible photocontrol of alov9 activity. a The activity of alov9 will decrease rapidly in a short time under the irradiation of $470 \mathrm{~nm}$ blue light. Then the enzyme activity will slowly recover in the dark state. $\mathbf{b}$ The activity of alov 9 will rapidly decrease with a strong irradiation. We keep lighting with weak intensity, and alov9 activity does not recover but remains at a certain level. All error bars show SEM $(n=3)$

suppression, including cofactor concentration, illumination intensity, and duration of illumination. Further analysis concerning the correlation between FMN concentration and light-induced inhibition level suggested that $0.2 \mathrm{mM}$ is preferable under the conditions used in our experiments (Fig. 3a). In the following experiments, alov9 activity was monitored while varying the light intensity. When alov9 was exposed to illumination of increasing intensity for $40 \mathrm{~s}$, higher intensities were found to induce a progressively decreasing rate of activity (Fig. 3b). The effects of irradiation time on alov9 excited at $470 \mathrm{~nm}$ exhibited a decrease similar to that of the light intensity (Fig. 3c). These results suggested that the inhibitory effect of blue light on alov9 underwent pronounced changes with varying illumination factors. Consequently, the enzyme activity of alov9 fusion can be controlled as desired by changing various factors under blue light excitation.

\section{Reversible regulation of alov 9}

To verify the stable reversibility of alov9 catalytic activity, the alov9 activity were analyzed through five cycles of illumination at $470 \mathrm{~nm}$ followed by incubation in the dark. The results showed that $87 \%$ of alov 9 activity could be maintained after four rounds of illumination (Fig. 4a). This suggested that irradiation shifts of alov9 from its physiological active state to a strongly inhibited state and that this process was reversible; alov9 recovered its native activity in the dark. In addition, the maintenance of alov 9 activity was achieved by varying the light intensity (Fig. 4b). Based on all of the evaluated results, it is suggested that the precise and reversible regulation of the alov9 fusion can be achieved.

\section{Conclusions}

In summary, based on the conformational change of the light-sensitive AsLOV2 domain, a method was successfully developed to reversibly photocontrol oxidase activity. We successfully constructed the alov9 fusion, in which the AsLOV2 domain was inserted into the allosteric sites of the AdhP protein, without interfering in the original AdhP activity. This alov9 fusion was indeed strongly inhibited upon exposure to blue light. Our results showed that alov9 fusion activity can be reversibly photocontrolled and still retain $87 \%$ of its initial activity after four illumination cycles. Finally, oxidase activity can achieve spatial and temporal control in a precise time. The control of protein activity via LOV2 insertion may prove to be a valuable tool for other biological processes in the future.

\section{Additional file}

Additional file 1: Figure S1. Three-dimensional structure of alov1-10 fusions. Figure S2. SDS-PAGE analsysis of the purification of alov1-10. Figure S3. Screening unconservative sites from surface-exposed loops by sequence alignment. Figure $\mathbf{S 4}$. Circular dichroism spectra of the alov9 under dark and light conditions. Table S1. The primers of alov1-10 fusions.

\section{Abbreviations}

alov9: AsLOV2-AdhP; AsLOV2: LOV2 domain isolated from Avena sativa; FMN: flavin mononucleotide; IPTG: isopropyl $\beta$-D-1-thiogalactopyranoside; LB: lysogeny broth; $\mathrm{OD}_{600}$ : optical density of bacteria at $600 \mathrm{~nm} ;$ PAS: Per-Arnt-Sim.

\section{Acknowledgements}

This work was funded by the National Natural Science Foundation of China (No. 21778018), Natural Science Foundation of Shanghai (19ZR1412700), and Research Program of State Key Laboratory of Bioreactor Engineering. 


\section{Authors' contributions}

TS conducted the experiments. TS and BZ drafted the manuscript. YR provided advice in the experiments design and data analysis. All authors read and approved the final manuscript.

\section{Funding}

This work was funded by the National Natural Science Foundation of China (No. 21778018), Natural Science Foundation of Shanghai (19ZR1412700) and Research Program of State Key Laboratory of Bioreactor Engineering.

\section{Availability of data and materials}

The dataset supporting the conclusions of this article is available.

\section{Ethics approval and consent to participate}

All the authors have read and agreed the ethics for publishing the manuscript.

\section{Consent for publication}

The authors approved the consent for publishing the manuscript.

\section{Competing interests}

The authors declare that they have no competing interests.

Received: 11 May 2019 Accepted: 26 July 2019

Published online: 07 August 2019

\section{References}

Betteridge PW, Carruthers RI, Cooper K, Watkin DJ (2003) CRYSTALS version 12: software for guided crystal structure analysis. J Appl Crystallogr 36:1487

Chen K, Li K, Deng J, Zhang B, Lin J, Wei D (2016) Carbonyl reductase identification and development of whole-cell biotransformation for highly efficient synthesis of (R)-[3,5-bis(trifluoromethyl)phenyl] ethanol. Microb Cell Fact 15:191-201

Christie JM, Reymond P, Powell GK, Bernasconi P, Raibekas AA, Liscum E, Briggs WR (1998) Arabidopsis NPH1: a flavoprotein with the properties of a photoreceptor for phototropism. Science 282:1698-1701

Crosson S, Moffat K (2001) Structure of a flavin-binding plant photoreceptor domain: insights into light-mediated signal transduction. Proc Natl Acad Sci USA 98:2995-3000

Dagliyan OM, Tarnawski PH, Chu D, Shirvanyants I, Schlichting NV, Dokholyan Hahn KM (2016) Engineering extrinsic disorder to control protein activity in living cells. Science 354:1441-1444

Halavaty AS, Moffat K (2007) N- and C-terminal flanking regions modulate light-induced signal transduction in the LOV2 domain of the blue light sensor phototropin 1 from Avena sativa. Biochemistry 46:14001-14009
Harper SM, Neil LC, Gardner KH (2003) Structural basis of a phototropin light switch. Science 301:1541-1544

Harper SM, Christie JM, Gardner KH (2004) Disruption of the LOV Jalpha helix interaction activates phototropin kinase activity. Biochemistry 43:16184-16192

Kawano FH, Suzuki A, Furuya Sato M (2015) Engineered pairs of distinct photoswitches for optogenetic control of cellular proteins. Nat Commun 6:6256

Lee S, Park H, Kyung T, Kim NY, Kim S, Kim J, Heo WD (2014) Reversible protein inactivation by optogenetic trapping in cells. Nat Methods 11:633-636

Lungu OI, Hallett RA, Choi EJ, Aiken MJ, Hahn KM, Kuhlman B (2012) Designing photoswitchable peptides using the AsLOV2 domain. Chem Biol 19(4):507-517

Pathak GP, Strickland D, Vrana JD, Tucker CL (2014) Benchmarking of optical dimerizer systems. ACS Synth Biol 3:832-838

Schwede T, Kopp J, Guex N, Peitsch MC (2003) SWISS-MODEL: an automated protein homology-modeling server. Nucleic Acids Res 31:3381-3385

Strickland D, Lin Y, Wagner E, Hope CM, Zayner J, Antoniou C, Sosnick TR, Weiss EL, Glotzer M (2012) TULIPs: tunable, light-controlled interacting protein tags for cell biology. Nat Methods 9:379-384

Swartz TE, Wenzel PJ, Corchnoy SB, Briggs WR, Bogomolni RA (2002) Vibration spectroscopy reveals light-induced chromophore and protein structural changes in the LOV2 domain of the plant blue-light receptor phototropin 1. Biochemistry 41:7183-7189

Thomas LM, Harper AR, Miner WA, Ajufo HO, Branscum KM, Kao L, Sims PA (2013) Structure of Escherichia coli AdhP (ethanol-inducible dehydrogenase) with bound NAD. Acta Crystallogr Sect F Struct Biol Cryst Commun 69:730-732

Wang H, Vilela M, Winkler A, Tarnawski M, Schlichting I, Yumerefendi H, Kuhlman B, Liu R, Danuser G, Hahn KM (2016) LOVTRAP: an optogenetic system for photoinduced protein dissociation. Nat Methods 13:755-758

Yu G, Onodera H, Aono Y, Kawano F, Ueda Y, Furuya A, Suzuki H, Sato M (2016) Optical manipulation of the alpha subunits of heterotrimeric $\mathrm{G}$ proteins using photoswitchable dimerization systems. Sci Rep 6:35777

Zhang K, Cui B (2015) Optogenetic control of intracellular signaling pathways. Trends Biotechnol 33:92-100

Zhang Q, Piston DW, Goodman RH (2002) Regulation of Corepressor function by nuclear NADH. Science 295:1895-1897

\section{Publisher's Note}

Springer Nature remains neutral with regard to jurisdictional claims in published maps and institutional affiliations.

\section{Submit your manuscript to a SpringerOpen ${ }^{\circ}$ journal and benefit from:}

- Convenient online submission

- Rigorous peer review

- Open access: articles freely available online

- High visibility within the field

Retaining the copyright to your article

Submit your next manuscript at springeropen.com 